\title{
RefleXIONes en Torno al Aprendizaje Autónomo
}

\author{
No deben llevar al niño únicamente a repetir \\ en iguales o nuevas palabras lo que acaba de oír. \\ Han de estimularlo a observar aquello que tiene ante él \\ y a afianzarse en lo que ha aprendido, \\ y ejercitarlo a hallar una pronta \\ y adecuada respuesta entre su pequeño acopio de conocimientos.
} PESTALOZZI, JOHANN HEINRICH

\author{
Por: Lyda P. Gil*
}

\section{Resumen}

El presente escrito inicia un discurrir orientado a indagar la pregunta sobre: ¿̇es posible hablar de aprendizaje autónomo en los discursos pedagógicos? y analizar así, las relaciones que se establecen entre autoridad autonomía, discurso pedagógico práctica pedagógica, estudiante docente. Presentando de manera sucinta las dimensiones conceptuales y pragmáticas en las que se fundamentan los discursos pedagógicos como discursos de poder, teniendo en cuenta los aportes de autores como Foucault, Berstein y Mario Díaz. Además, se toma como ejemplo de un discurso pedagógico el modelo constructivista desde la perspectiva de Vygotski y Carretero, estableciendo cómo el desarrollo del individuo deviene en procesos de aprendizajes autónomos. Para finalmente, establecer, desde una breve presentación de un discurso pedagógico constructivista, cómo el discurso pedagógico puede plantear aprendizajes autónomos.

\section{Palabras Claves}

Aprendizajes autónomos, discurso pedagógico, práctica pedagógica, constructivismo.

\section{REFLECTIONSRELATED TOAUTONOMOUS LEARNING}

\begin{abstract}
This paper begins by discussing the following question: Is it possible to learn from autonomous learning in the pedagogic discourses? And therefore to analyze the relations that are established between authority and autonomy, pedagogic discussion and practical pedagogic, student and teacher. Therefore presenting in a concise way the conceptual and pragmatic dimensions that are founded in pedagogic discussions, such as power debates. All of this taking into account authors such as: Foucalt, Berstein and Mario Díaz. Also, as an example of a pedagogic debate within the constructivist model from Vygotski and Carretero's point of view. It establishes that the individuals self development comes from autonomous learning. And finally, to establish from a brief constructivist pedagogic presentation how the pedagogic discussion can suggest autonomous learning.
\end{abstract}

\section{Key words}

Autonomous learning, pedagogic discussion, practical pedagogic, constructivism

Recibido, 25 de mayo de 2007; aprobado, 15 de junio de 2007 


\section{INTRODUCCIÓN}

La acción educativa se ha planteado en un primer momento desde una cuestión discursiva, mas ésta no es la única que se tiene que tener en cuenta, sino, que hay que comprender toda la trama que se encuentra alrededor de la acción. Un entramado que consta de procesos propios de cada acción, pero que a la vez, se conjugan entre sí. Estos procesos son los que han transformado la escuela y le han dado una nueva estructura, dentro de la cual los estudiantes se presentan como transformadores sociales, en la medida que pueden ejercer su autonomía y, de esa manera, la escuela se convierte en un espacio para que los estudiantes ejerzan su libertad.

Pero, qué se encuentra a la base de los procesos educativos, qué es lo constituyente. Uno de los elementos que se encuentra inmerso en los procesos de aprendizaje son los discursos que la entretejen, discursos que van desde la mera teoría a la práctica en el aula. Por tal motivo, el presente artículo pretende realizar una reflexión teórica sobre cómo se presentan aprendizajes autónomos en la acción educativa a través de los discursos pedagógicos ${ }^{1}$ que son establecidos para la misma. Centrándonos en el análisis del discurso de la propuesta pedagógica constructivista, pues bien sabido es que el constructivismo busca que los estudiantes desarrollen conocimiento por si mismos.

De acuerdo con lo anterior, la exposición de la presente reflexión abordará en un primer momento, y como parte del análisis del papel del discurso en la educación, la pregunta por cómo el discurso puede ser utilizado como un dispositivo de poder. Lo cual avoca a mirar cómo el discurso constructivista entreteje un discurso de poder propio, inherente a los procesos pedagógicos que se buscan desarrollar en las instituciones educativas.
Posteriormente, teniendo en claro el papel del discurso pedagógico se realizará una reflexión entorno de las concepciones de los procesos de aprendizaje que plantea Vigosky, realizando, a la vez, un paralelo de estos procesos con la educación, con un matiz especial que tendrá como mirada el lenguaje. Desde esta perspectiva, lo primero a abordar es una breve presentación de este autor y de las posturas constructivistas. Además, se buscará trabajarlas desde una perspectiva que se oriente hacia el problema de centrar qué es de los aprendizajes autónomos. Para tal fin, se tomará como base los textos de Mario Carretero "¿Qué es el constructivismo?" y "Desarrollo cognitivo y aprendizaje" en Constructivismo y educación. En dichos textos se expone la postura constructivista y se plantean herramientas para dar una solución al interrogante anteriormente planteado. Estableciendo relaciones entre lenguaje y constructivismo, y cómo esto se relaciona con los aprendizajes autónomos.

\section{EL DISCURSO COMO DISPOSITIVO DE PODER}

El propósito del presente apartado es presentar una definición de discurso pedagógico y cómo éste se emplea, desde autores como Bernestein y Mario Díaz, como mecanismo de poder en la escuela desde distintas perspectivas. Esto avocara a examinar, desde qué perspectiva el modelo constructivista como un discurso pedagógico y, además, planteará la pregunta por si éste es otro discurso de poder, que se maneja en educación para la formación de los individuos y si es así, cómo se puede hablar desde el discurso de aprendizajes autónomos.

Por ello, es claro decir que no es novedoso el planteamiento de esta idea, pues diversos autores han establecido la educación ${ }^{2}$ como un mecanismo de control, una forma de poder, pues

1 Aunque la discusión respecto a este tema es bastante amplia y los diferentes pedagogos han abordado el concepto de discurso pedagógico desde diferentes perspectivas. Para fines propios del presente escrito no se trataran dichas discusiones, sino que se expondrá la que comprende a la escuela como un dispositivo de control, pues ella permite mirar cómo se pueden dar aprendizajes autónomos de acuerdo con el discurrir que se tenga a la base, pues se ve al discurso pedagógico como un discurso sin discurso especifico, desde una perspectiva como la de Bernstein.

2 La educación institucionalizada como regularizadora 
en sí mismo es un mecanismo para tal fin. Uno de los autores que busca presentar esta idea es Mario Díaz en su artículo: "Pedagogía, discurso y poder", en el cual busca definir el carácter mediático de la pedagogía "en función de la transmisión social y cultural de órdenes simbólicos dominantes" ${ }^{13}$. Además, agrega Díaz, en la introducción de su obra que "intenta examinar las relaciones entre la pedagogía, su función discursiva y sus prácticas de control, transformación y reproducción de los discursos y del poder ${ }^{114}$. Con lo que presenta no una propuesta o un método pedagógico nuevo, sino los elementos teóricos necesarios para interpretar la "pedagogía como un dispositivo de transmisión cultural" ${ }^{\prime 5}$, lo cual se encuentra en relación con lo planteado por $V_{y g o t s k i}{ }^{6}$ al establecer que el conocimiento se funda en un contexto social y cultural. Por otro lado, una posible conclusión a la que llega el artículo de Díaz, se puede sintetizar en las siguientes preguntas: por qué la pedagogía es un dispositivo de transmisión y cómo el discurso pedagógico es una forma de poder, asuntos que son de vital importancia para el presente apartado.

Lo primero que hay que tener en cuenta es que Díaz tiene como punto de referencia de su análisis, lo planteado por Bernstein. Para quien "el discurso pedagógico es un discurso sin discurso especifico: no tiene un discurso propio. Es un principio para apropiarse de otros discursos e introducirlos dentro de una relación de transmisión y adquisición selectivas" ${ }^{\prime \prime}$. Es, desde esta concepción, que se plantea al discurso psicológico constructivista como un discurso pedagógico, pues en un primer momento éste surge como una propuesta distinta para comprender el actuar humano y es adaptado a las necesidades propias de la pedagogía. Asimismo, Bernstein concibe el discurso pedagógico como dispositivo de poder que busca integrar "la habilidad en el orden y el orden en la habilidad" ${ }^{8}$.

Además, el discurso psicológico crea "el lenguaje que se estaría en vías de encontrar comparaciones fecundas entre el simbolismo del inconsciente y ciertos procedimientos típicos de la subjetividad manifestada en el discurso". Con esto el discurso se hace cada vez más estricto y se va encerrando en cierta disciplina que lo valida ante las demás y se restringe a los demás, únicamente a nivel teórico, pues se ciñe a cierto lenguaje particular.

Además de Bernstein, Díaz realiza su análisis del discurso y el discurso de poder desde otro enfoque, o como él mismo lo expresa: "nuestro examen del dispositivo pedagógico busca integrar los principios, conceptos y reglas propuesta por Foucault en su análisis genealógico. Este examen gira entorno a las relaciones entre poder, discurso, control y sujeto" ${ }^{10}$. Razón por la cual, es prudente comenzar por comprender que entiende Foucault por discurso y por poder, analizando las relaciones que pueden existir con el concepto de aprendizajes autónomos. Para tal fin, es necesario tener claro ¿¿Qué es un saber? y ¿QQué es un discurso? Michel Foucault habla del saber y lo define al igual que el discurso, remitiéndonos a un campo amplio. Su objeto es el saber, entendido como:

el dominio constituido por los diferentes objetos que adquirirán o no un estatuto científico; es también de campo de coordinación y de subordinación de los enunciados en los que los

3 DÍAZ, M. y MUÑOZ, J. "Pedagogía, discurso y poder". En Pedagogía, discurso y poder. Corpodic. Bogortá. 1990. p. 40

4 Ibídem.

5 Ibídem. p. 41 . Además, a este respecto opina Bernstein que el dispositivo de pedagógio "es la condición para la producción, reproducción y tranformacion de la cultura" (BERNSTEIN, Basil. "Sobre el discurso pedagógico". En La construcción social del discurso pedagógico. Editor: Diaz, Mario. El Griot. Bogotá. 1990. p. 122)

6 Estructuralmente los postulados de Vygoski y del constructivismo se presentarán en el siguiente apartado para una mayor comprensión de los mismos a la luz de lo que es un discurso pedagógico.

7 BERNSTEIN, Basil. "Sobre el discurso pedagógico". En La construcción social del discurso pedagógico. Editor: Diaz, Mario. El Griot. Bogotá. 1990. p. 127

8 lbídem. p. 129

9 Ibídem. p. 137

10 DÍAZ, M. y MUÑOZ, J. "Pedagogía, discurso y poder". En Pedagogía, discurso y poder. p. 46 
conceptos aparecen, se definen, se aplican y se transforman; en fin, un saber se define por las posibilidades de utilización y de apropiación ofrecidas por el discurso".

El enunciado de un cuerpo que circunda y es atravesado por otro sin número de enunciados que se van transformando y se van insertando en un grupo de personas conformando así un saber, pero se puede insertar en una disciplina estructurándolo, como también puede estar disperso y quedar en el espacio que circunda. Este saber, hay que tener claro, al igual que con el discurso, representa en un tiempo y un espacio determinado.

El discurso es el que se circunscribe en una disciplina que lo hace un saber específico, para convertirse dicho conocimiento en ocasiones en una ciencia $^{12}$ de una serie de asociaciones que lo hacen verdadero para un grupo determinado y que sólo lo pueden manejar ellos. Son unos complejos sistemas de restricción de la realidad, en el que sólo pueden participar los que estén cualificados para ello, ya que hay ciertos aspectos o temas de la realidad que no todo el mundo conoce, porque no todo el mundo puede saberlo todo sobre todo.

Y por último, es necesario tener claro que la concepción de poder de Foucault no reprime al sujeto humano, no se mantiene ni se prolonga hacia el futuro con base en la represión, sino que, al revés, le inyecta o inocula unos ciertos saberes, los cuales normalizan al sujeto y se convierte en el arma notable del poder para ejercer sus potestades $y$, por fin, existir como operador de dominancia. Más żdónde queda la autonomía?, ¿Qué papel juega dentro de esos saberes normalizantes?, ¿Qué implica la normalidad? Si se tiene en cuenta que para Foucault la concepción de poder no implica un reprimir al ser humano sino un encauzar, entonces, habría que analizar el papel de los agentes y de las relaciones de poder que estos establecen, analizando cómo y para qué existen las figuras de autoridad, donde el dispositivo pedagógico es "un regulador simbólico de la conciencia en su selectiva creación, posición y oposición de sujetos pedagógico; es la condición para la producción, reproducción y transformación de la cultura" ${ }^{\prime 13}$. Cabe agregar, que con la idea de normalización, se establece la necesidad de una homogeneidad, dentro de la cual los aprendizajes autónomos quedarían relegados, pues se perdería de vista el ejercicio de la voluntad. Mas para Foucault esa homogeneidad se da de forma individualizada, pues cada individuo tiene sus propios niveles, los cuales son determinados por la psicología y sus propias especialidades, las cuales se establecen a través del proceso de formación de cada individuo y la homogeneidad lo que permite es hacer útiles las diferencias que existen entre unos y otros, para ajustarlas entre sí.

Además, desde la perspectiva planteada anteriormente, es necesario un discurso que validará la normalidad del saber pedagógico y la formación de los estudiantes, por eso se plantean discursos de poder como el médico, el psiquiátrico, el jurídico y, en último término, el pedagógico, a través de una vuelta a la psicología, razón por la cual se abordará lo que se plantea de este último, para establecer el enlace con el discurso pedagógico. Además, respecto a los discurso Foucault va a plantear que existen relaciones entre ellos, es decir, los discursos jurídico-médico-psiquiátrico actúan o recaen sobre esa infancia para así poder diagnosticarla, analizarla, juzgarla y corregirla; en donde se busca poder controlar a ese niño que puede irse en contra de los ideales ya propuestos por la civilización. El discurso jurídico necesita del médico-psicológico para poder tomar la decisión de la corrección que se le ha de dar al infante. Pero no sólo la corrección, sino también evaluar en qué estado se encuentra el delincuente para dictaminar la acción a tomar. Así mismo, el psicológico-médico necesita del jurídico para validar su discurso y viceversa.

11 FOUCAULT, Michel. Antropología del saber. Gredos. Madrid. 1970. p. 306

12 Pero żqué ocurre cuando al discurso no se circunscribe a una ciencia? O ¿̇deja de ser discurso? Este es un tema que avocaría a otros objetivos que no son de interés para el presente escrito, mas cabe dejarlo como interrogante para posteriores análisis.

13 BERNSTEIN, Basil. "Sobre el discurso pedagógico". En La construcción social del discurso pedagógico. Op. cit. $p, 134$ 
La psicología determina los comportamientos de la moral ${ }^{14}$ y del nivel intelectual del individuo, así "los futuros psicólogos se convertirán en los especialistas de tratados de estas fronteras. Los médicos por su parte proponen distinciones del mismo tipo para diferenciar su campo de acción del de los psiquíatras, afirmando la necesidad de las competencias médicas"15. Es así como lo médico y lo psicológico se separa, el uno del otro centrando cada uno su objeto de estudio. Por un lado, la psicología se encargará de la conducta de los niveles de pensamiento del individuo y la medicina de los procesos y desarrollos fisiológicos del individuo. Así, la medicalización se aleja de la escuela dejando unas características de ésta, pero dando paso a la psicología para que seleccione los anormales y esté asociada al tema de la seguridad (sobre la vida), o más ampliamente, a todo lo que supone una garantía contra los riesgos improvistos del futuro. Es aquí donde es de vital importancia el rol del discurso constructivista, al establecer estructuras en los procesos de aprendizaje, en los cuales, a través de un análisis psicológico, se parametriza al individuo y se determina su saber de acuerdo a ellos.

Es así como la psicología se va instaurando como un discurso valedero y necesario para todos, en donde su rigurosidad es enfatizada para unos cuantos y no todos, que son los que manejan el discurso, porque "se fundamenta un discurso científico que va a desarrollar la noción de interpsicología, (...) de que medios de corrección puede echar mano el niño respecto a sus padres en aquellos casos en los que los padres estén muy descontentos de su conducta"16. Aquí cabe cuestionar, por los procesos de selección que se llevan en el colegio cuando se realizan las entrevistas a los estudiantes nuevos y los mecanismos de control que se utilizan con los denominados casos problema, los cuales se encuentran tratados dentro del ámbito de lo psicológico.

¿Dónde queda entonces el discurso pedagógico? Anteriormente, se definió, en términos de Bernstein, más con la panorámica que abren los planteamientos de Foucault, como "el instrumento de transformación del conocimiento teórico en conocimiento pedagógico y como el medio de imposición de normas y prácticas ideológicas y culturales ${ }^{117}$.

En esa medida, el discurso pedagógico se presenta como un transformador y regulador del conocimiento, que no es constante, ni uniforme. Donde se dan dispositivos de control y poder, realizando una transformación de la cultura, porque, como se ha dicho tradicionalmente, el conocimiento es poder. Por ende, "en la escuela el dispositivo pedagógico -como un bloque articulado- actúa sobre la formación/distribución de competencias especializadas a través de la distribución de discursos/prácticas especializadas" ${ }^{118}$. Además, este dispositivo sirve de vínculo en la escuela entre "poder, conocimiento y conciencia, el cual es el regulador simbólico para la ubicación de la conciencia, la especialización del sujeto. (...) El dispositivo pedagógico es, esencialmente, un discurso que sirve para traducir las relaciones de poder en discursos de control simbólico y para traducir los discursos de control simbólico en relaciones de poder ${ }^{\prime \prime 19}$. Es decir, el encargado de establecer enlaces y de poner de manifiesto las transformaciones que se dan en los discursos, lo cual implica que el individuo se encuentra inmerso en una multiplicidad de discursos que parametrizan su actuar en la cultura.

El discurso pedagógico puede ser entendido como una forma de poder, desde esta perspectiva, debido a la organización, distribución y selección que se da de los discursos.

14 Lo que llevaría a un análisis de los actos volitivos. Cfr. VYGOTSKI, L. "El problema de la voluntad y su desarrollo en la edad infantil". En Obras escogidas. Visor. Madrid. 1193.

15 MUEL, Francine. 1993. Espacios de poder. Trotta. Sevilla. p. 133

16 Ibídem. p. 131

17 DIAZ, M y MUÑOZ, J. "Pedagogía, discurso y poder"'. En Pedagogía, discurso y poder. Op. cit. p. 42

18 Ibídem. p. 51

19 BERNSTEIN, Basil. "Sobre el discurso pedagógico". En La construcción social del discurso pedagógico. Op. cit. $\mathrm{p}, 142$. 
Además, Bersntein plantea que el discurso es un medio que permite traducir el control simbólico, mediante relaciones de poder, en las cuales se establecen una serie de reglas de distribución que tienen como fin la regulación de las relaciones que se establecen entre poder y grupos sociales, conciencia y práctica, reproducciones y producciones $^{20}$. Controlando con ello qué se debe y qué no se debe pensar, pues, al ser regulador, establece el tipo de producción que debe extraerse de la escuela. Además, lo pensable es aquello que se encuentra en potencialidad en el lenguaje del individuo, aquello que al igual que el discurso, es un medio de transmisión cultural y permite la potencialización de los contextos sociales. Portanto,

Las reglas distributivas señalan y distribuyen quién puede transmitir que a quien y bajo que condiciones, y al efectuarlo procuran establecer los limites exteriores e interiores del discurso legitimo, entonces el discurso pedagógico se considera como las reglas de comunicación especializada a través de las cuales los sujetos pedagógicos se crean selectivamente. ${ }^{21}$

Para Bernstein el discurso pedagógico además de tener reglas de distribución se constituye de reglas de recontextualización, que se encarga de transformar lo real en algo virtual o imaginario. En este sentido, es que se entiende al discurso pedagógico que se apropia de los planteamientos de otros discursos. Es esta regla de recontextualización la que permite entender cómo una concepción psicológica, como la constructivista, termina convirtiéndose en un discurso pedagógico valido.

Lo anterior da cabida a preguntarse cómo se entiende, desde la perspectiva psicológica del constructivismo, el aprendizaje. Desde esa perspectiva se busca analizar la posibilidad de hablar de aprendizajes autónomos en los discursos pedagógicos. Pues, hasta este punto, se ha comprendido al discurso pedagógico como un regulador del aprendizaje y como un dispositivo de poder, lo cual no daría lugar a la pregunta por los aprendizajes autónomos. Más, lo que entraña esta misma situación, es la necesidad establecer al interior de los discursos la apertura de los mismos, en donde la escuela pasaría de ser un mero mecanismo de control, para ser entendida como un espacio de desarrollo de aprendizaje autónomo.

\section{DESPLIEGUE DE LA AUTONOMÍA EN EL DISCURRIR CONSTRUCTIVISTA}

\author{
¿No te das cuenta de que has querido \\ combatir la ignorancia con la instrucción, y que \\ la instrucción es la afirmación de la ignorancia \\ porque destruye la creatividad?
}

Humberto Maturana

En medio de una indagación, como la que se propone en el presente texto, resulta necesario dilucidar las ideas planteadas por el constructivismo como modelo psicológico y de pensamiento pedagógico, lo cual permite tener una concepción clara de su significado y vislumbrar sus implicaciones en el desarrollo de la autonomía de los estudiantes en el aula de clase. Algunos autores definen el constructivismo como: "una perspectiva epistemológica basada en la afirmación de que los seres humanos crean activamente las realidades a las que responden" ${ }^{22}$ y "la esencia del constructivismo es el individuo como construcción propia, que se va produciendo como resultado de la interacción de sus propias disposiciones internas y su medioambiente, y su conocimiento no es una copia de la realidad" ${ }^{23}$.

A partir de esto, se puede decir que el eje central de los postulados del constructivismo versa en comprender que el acto de la enseñanza es constituido por dos sujetos que son partícipes de dicha acción, pues se plantea que el estudiante es un sujeto que tiene algo que aportar a sus procesos de aprendizaje y como sujeto activo construye, a través de la interacción con los

20 lbídem. p. 123

21 Ibídem. p. 127

22 LYDDON, William. "Formas y facetas de la psicología constructivista". En Construcciones de la experiencia humana comp.. PAKMAN, Marcelo. Gedisa, Barcelona. 1997. p. 89

23 CHADWICK, Clifron. "La psicología de aprendizaje del enfoque constructivista". En Red Revista Latinoamericana de Estudios Educativos. México, 2006. p. 121 
demás, su propia interpretación y perspectiva de la realidad. En esta interacción de subjetividades, el docente y los pares participan como agentes mediadores de los procesos, haciendo uso de la instrucción y compartiendo experiencias. Lo cual evidencia que "todo tipo de aprendizaje que el niño encuentra en la escuela tiene siempre una historia previa" ${ }^{24}$. Al respecto, Carretero plantea que el constructivismo

es la idea que mantiene que un individuo tanto en los aspectos cognitivos y sociales del comportamiento como en los afectivos- no es un mero producto del ambiente ni un simple resultado de sus disposiciones internas, sino una construcción propia que se va produciendo día a día como resultado de la interacción entre esos dos factores. En consecuencia, según la posición constructivista, el conocimiento no es una copia de la realidad sino una construcción del ser humano. ${ }^{25}$

Dicha construcción es abordada en el constructivismo desde distintas perspectivas teóricas como son la de Piaget y la de Vygotski; las cuales, vale la pena resaltar por su aporte significativo a los proceso de aprendizaje y desarrollo. Sin embargo, para los fines del presente artículo se desarrollará la propuesta de Vygotski como eje central para la explicación del modelo constructivista.

Por una parte, Piaget plantea que el ser humano experimenta un desarrollo teleológico y por estadios; en los cuales cada individuo organiza su acción a partir de esquemas 0 estructuras que van desde las más simples a las más complejas; en un proceso continuo y de cambio constante. Además, concibe que existen unas funciones constantes a lo largo del desarrollo como son la asimilación, la acomodación y la organización. Es decir, el individuo, asimila la información del medio circundante a través de todos sus órganos sensoriales; dicha información es organizada en estructuras de conocimiento simples y variables, es decir, en esquemas que van configurando un modo de pensar y actuar; y, que posteriormente, se van confrontando con las nuevas experiencias que el individuo adquiere en relación con el mundo. Este proceso se conoce como acomodación, en el cual la nueva información crea un desequilibrio en el organismo al confrontarse con los esquemas establecidos previamente, generando una nueva organización que evidencia un cambio en la estructura de conocimiento e implica algún grado de sistematización dependiendo del nivel o estadio de desarrollo en que se encuentre el individuo. Es así, como el desarrollo intelectual se encuentra en un constante cambio y complejización de sus estructuras y razonamientos; es decir, que entre más móvil sea el desarrollo también será más estable ${ }^{26}$.

Esto conlleva a ver que la propuesta constructivista, desde el punto de vista piagetiano, plantea que los individuos tienen una serie de esquemas, que les permiten realizar procesos de asimilación y acomodación, por medio de los cuales se dan los procesos de aprendizaje. Para Carretero "un esquema es una representación de una situación concreta o de un concepto que permite-manejarnos internamente y enfrentarse a situaciones iguales o parecidas en la realidad" ${ }^{27}$. De acuerdo a esto, la representación que cada individuo tiene del mundo, es una construcción propia, que depende de los esquemas que cada uno tiene.

Por otro lado, Vygotski concibe la construcción propia del individuo como un proceso de internalización de la cultura, donde los otros, como agentes socializadores y mediadores, apoyan y contribuyen en el desarrollo del mismo. En otras palabras, el individuo se construye en relación con los otros a través de un proceso que va desde el campo interpersonal cultural y social- hasta el intrapersonal; donde la comunicación y el

24 VYGOTSKI, L. "Desarrollo y aprendizaje". En El desarrollo de los procesos psicológicos superiores. Grijalbo, Barcelona, 1989, p. 131.

25 CARRETERO, Mario. "¿̇Qué es el constructivismo? En Constructwumo y educación. Aigue Grupo Editor, Buenos Aires. 1993 p. 20

26 PIAGET, Jean. "El tiempo y el desarrollo intelectual del niño". En Seis estudios de Psicología. Labor. Bogotá. 1995. p. 132

27 CARRETERO, Mario. "¿Qué es el constructivismo? En Constructwumo y educación. Op. cit. p. 21 
lenguaje, como una herramienta psicológica fundamental ${ }^{28}$, permiten la interacción y la comprensión del mundo.

Este postulado de Vygotski permite ampliar el ideal de autonomía que se puede construir desde la propuesta constructivista, pues se necesita del otro para la construcción de la propia autonomía y es en diálogo permanente, que el individuo se reconoce como persona que se autoforma, pero que, a la vez, necesita del otro para definirse y constituir su ser. Un ser que se encuentra inmerso en el lenguaje, pero que no se subsume a éste, como tampoco el lenguaje se subsume al hombre.

De esta manera, el ser humano al interactuar con otros va configurando un modo de ser, una cultura a través del lenguaje ${ }^{29}$, el cual a su vez tiene importantes implicaciones en el desarrollo del pensamiento y la cultura de los pueblos $^{30}$. Este punto es un eje central de la teoría Vygotskiana que ayuda a comprender cómo influye el lenguaje y los principios del constructivismo en el desarrollo de la autonomía. Pues el lenguaje, como mediador en la comunicación del ser humano, le permite construirse y socializarse colaborando en el desarrollo de las funciones psicológicas superiores, lo cual implica que el actuar no se encuentra dado únicamente por el mundo externo, sino, que es un ser capaz de actuar deliberadamente desde su propia voluntad, que se genera del constante interactuar con otros seres, que aportan elementos a la constitución de su propia personalidad y pensamiento. Además, el lenguaje guía, determina y prevé la acción del ser humano, ya que "el lenguaje surge, en un principio, como un medio de comunicación entre el niño y las personas de su entorno. Solo más tarde, al convertirse en lenguaje interno, contribuye a organizar el pensamiento del niño, es decir, se convierte en una función interna" ${ }^{\prime \prime 2}$.

El individuo, desde las primeras interacciones con otro ser humano está inmerso en un mundo simbólico y del lenguaje y aunque no comprenda en su totalidad el significado de las palabras y no pueda articularlas en los primeros años de vida. El hecho de estar en contacto directo con ese universal simbólico va generando procesos internos que, más adelante, van a configurar su pensamiento, su mundo interno. Por ejemplo, en un primer momento de la socialización, el niño descubre que es incapaz de resolver un problema por sí solo, así que se dirige hacia el adulto y le hace saber lo que no puede hacer, pero, luego este lenguaje socializado, se interioriza y en lugar de recurrir al adulto recurre a sí mismo, pasando del plano interpersonal al intrapersonal donde, por primera vez, con la aparición del mundo simbólico al interior del niño, convergen los procesos de pensamiento y lenguaje, haciendo verbal el pensamiento e

28 Según Vygostki, el desarrollo de herramientas psíquicas determina las relaciones humanas con su entorno y consigo mismas. Las herramientas psíquicas son análogas a las herramientas industriales y se caracterizan también por ser producidas por la actividad social y no por originarse orgánicamente (vygotski, 1985-1987, pag.309). Las herramientas psíquicas pueden ser sistemas muy complejos; como ejemplos, Vygotski menciona al lenguaje hablado, los sistemas de notación, las obras de arte, el lenguaje escrito, los esquemas, diagramas, mapas y dibujos. (HEDEGAARD, Mariane. "La zona de desarrollo próximo como base para la enseñanza". En Vygostki y educación. Comp: MOLL, Luis. Alque. Buenos Aires. 1993. p. 405)

29 Esta concepción de lenguaje se encuentra también en un autor como Wittgenstein, quien encuentra que cuando se aprende un lenguaje también se aprende su uso, lo cual esta determinado por el grupo que utiliza ese lenguaje, me atrevería a afirmar que a lo que se refiere Wittgenstein es que el uso, a la vez, implica un conocimiento de la cultura, del entramado de toda la comunidad. (Cfr. Wittgenstein, L. Investigaciones Filosóficas. Gredos, Madrid, 1995. Parágrafo 9).

30 Hay que tener en cuenta que en este punto se va a entender al lenguaje como un transmisor de cultura, pues ésta es la concepción que maneja Vygosky y otros autores. Además, el lenguaje, en cierta forma, es pieza fundamental en la estructuración de la persona, pues, el lenguaje pone de manifiesto todo su actuar. Es aquí donde se encuentra la relación entre discurso y lenguaje, pues ambos son transmisores y transformadores de la cultura, pues el lenguaje no puede ser entendido como una mera forma de comunicación, pues dicho concepto no abarca en totalidad lo que se encuentra inmerso en el mismo.

31 VYGOTSKI, L. "Desarrollo y aprendizaje". En El desarrollo de los procesos psicológicos superiores. Op. cit. p. 138 
intelectual al lenguaje. Así, el niño cada vez más se apoya en el lenguaje para pensar y lo utiliza para resolver problemas ${ }^{32}$.

Ante esto, Vygotski hace referencia al desarrollo de los seres humanos en tres dominios el filogenético, el ontogenético y el histórico cultural que se caracterizan por sufrir cambios denominados saltos cualitativos y se pueden presentar paralelamente en cada uno de los dominios. En este punto cabe decir, que a nivel de la filogénesis, se presenta una fase preintelectual en el desarrollo del habla y una fase prelinguística en el desarrollo del pensamiento, pero pensamiento y lenguaje se unen sólo cuando aparece la especie humana, la función simbólica ${ }^{33}$.

A nivel de la ontogénesis, el niño atraviesa por varias etapas: 1. El niño actúa sin necesidad de las palabras. 2. El lenguaje acompaña las acciones del pequeño, es decir, que el lenguaje está provocado y dominado por la actividad. Los niños hablan sobre lo que hacen o lo que pasó. 3. El lenguaje guía, determina y domina el curso de la acción, hasta llegar a preceder a la acción y toma la función de planificar las acciones del futuro, entonces se convierte en una función organizadora de la actividad simbólica, dando origen a las formas más puramente humanas de la inteligencia práctica y abstracta, es decir, se llega a la integración plena del lenguaje y la actividad práctica que antes eran independientes ${ }^{34}$.

Asimismo, es importante decir que en el paso del lenguaje externo al internalizado, existe el lenguaje egocéntrico, el cual es un eslabón fundamental; ya que le permite al niño comunicarse consigo mismo y regula su acción. Para Vygotski es la forma transicional entre el lenguaje externo al lenguaje interno. Todo esto, lenguaje y pensamiento, configuran entonces el modo de actuar con el mundo. Esto se evidencia en el siguiente planteamiento que, según Mariane Hedegaard, Vygotski plantea,

El aspecto interpersonal de la psiquis humana apareció primero como actividad practica entre los seres humanos. El uso de herramientas compartidas y colectivas es parte de esta actividad práctica interhumana. Los procedimientos interpersonales para el uso de herramientas gradualmente se convirtieron en procedimientos intrapsíquicos adquiridos. Mediante los procedimientos para usar herramientas, los humanos son portadores de tradiciones históricas sociales; consecuentemente, la actividad interhumana, en la medida en que forma la actividad interior del niño, es siempre social, histórica y cultural. ${ }^{35}$

Por su parte el dominio histórico- cultural de acuerdo con Vygotski favorece el desarrollo de las funciones psicológicas culturales o superiores; las cuales se caracterizan por el control voluntario, la realización consciente, por tener orígenes sociales y la mediación del empleo de herramientas psicológicas como los símbolos y el lenguaje. Mientras que las funciones psicológicas naturales o inferiores que se caracterizan por el control del entorno natural, una ausencia de realización consciente, por tener orígenes individuales y por una falta de mediación mediante herramientas psicológicas ${ }^{36}$. Según Vygotski, el paso de las funciones psicológicas elementales a las superiores, se da gracias al contexto cultural y a la interacción social que tiene los individuos, experimentando así, un salto cualitativo en su desarrollo, con nuevos principios explicativos y nuevas formas de mediación, como son, en este caso los adultos y el universo simbólico que han construido a lo largo de la historia. ${ }^{37}$ Con lo cual, se promueve la toma de decisiones de manera voluntaria y consciente, consolidando la autonomía en los individuos.

32 Cfr. VYGOTSKI, L. "Las raíces genéticas del pensamiento y lenguaje". En Obras escogidas. Visor. Madrid. 1993. p. 72 - 75

33 Cfr. Ibídem. p. $66-67$

34 Cfr. Ibídem. p. $69-71$

35 HEDEGAARD, Mariane. "La zona de desarrollo próximo como base para la enseñanza". En Vygostki y educación. Comp: MOLL, Luis. Alque. Buenos Aires. 1993. p. 405

36 Cfr. WERTSCH, James. "El método de Vygotski". En Vygotski y la formación social de la mente. Paidós, Barcelona. 1995. p. 44 
De manera complementaria, el discurso constructivista aporta elementos que favorecen al desarrollo de la autonomía, como lo es el de la zona de desarrollo próximo; en la cual según Vygoski, citado por Mariane Hedegaard:

El niño puede copiar una serie de acciones que sobrepasan sus habilidades, pero sólo dentro de ciertos límites. Copiando el niño es capaz de desempeñarse mucho mejor con los adultos y guiado por ellos que solo, y puede hacerlo con comprensión e independencia. La diferencia entre el nivel de las tareas resueltas que se pueden realizar con la guía y ayuda de los adultos y el nivel de tareas resueltas de manera independiente es la zona de desarrollo próximo. ${ }^{38}$

Yagrega Jonathan Tudge:

La zona de desarrollo próximo define aquellas funciones que aún no han madurado pero se hallan en proceso de maduración; funciones que han de madurar mañana, pero que ahora se encuentran sólo en estado embrionario. Esas funciones podrían ser descritas como los "brotes" - las "flores" del desarrollo, más bien que como los "frutos" del desarrollo. (1978, pag.86) ${ }^{39}$

Por consiguiente, al partir del nivel de desarrollo del alumno, en el cual se busca establecer aquellas funciones que el niño ha desarrollado ${ }^{40}$, con el aporte y guía de los adultos o pares más capacitados, se puede asegurar una construcción de aprendizajes significativos en la escuela. Ya que es un espacio de socialización que le permite al niño interactuar con un mundo simbólico y científico, que paulatinamente va a ayudarle a desplegar todas sus capacidades y, a su vez, le brinda herramientas para el desarrollo de las funciones psicológicas superiores, que como se ha mencionado anteriormente, facultan al individuo para ejercer acciones volitivas y concientes. Es decir, que con la enseñanza y la interacción social el ser humano se torna cada vez más conciente y responsable de su propio proceso de formación, en un ser más capaz de pensar y tomar decisiones por sí mismo y de realizar aprendizajes significativos por su propia cuenta. De ahí que se pueda decir, que el aprendizaje autónomo debe ser un objetivo fundamental de la escuela; la cual, de acuerdo con Hedegaard se caracteriza, principalmente, por crear la zona de desarrollo próximo, estimulando una serie de procesos de desarrollo interior. $^{41}$ Estas ideas se evidencian en los planteamientos que Vygotski realiza al respecto:

Desde este punto de vista, no se puede identificar a la enseñanza como desarrollo, sino que la enseñanza adecuadamente organizada dará como resultado el desarrollo intelectual del niño, dará existencia a toda una serie de procesos de desarrollo, que no eran posibles sin enseñanza. Así, la enseñanza es un factor necesario y general en el proceso de desarrollo del niño, no de las características naturales del hombre sino de las históricas $^{42}$

En este punto se podría considerar, a manera de conclusión, que la propuesta constructivista desde los planteamientos anteriormente expuestos- permite que el individuo desarrolle aprendizajes autónomos, pues cuando se habla de construcción propia lo que se hace es designar una autonomía en los procesos que lleva a cabo el individuo. Además, avoca a entender que, en medio de esa interacción permanente que tiene el individuo con la realidad, se establecen procesos comunicativos que se dan mediante el lenguaje, mas éste no es su simple resultado sino también una disposición interna del ser humano, que al encontrarse en un contexto favorece la construcción de nuevos esquemas conceptuales.

37 VYGOTSKI, L. "Desarrollo y aprendizaje". En El desarrollo de los procesos psicológicos superiores. Op. cit. p. 132

38 HEDEGAARD, Mariane. "La zona de desarrollo próximo como base para la enseñanza". En Vygostki y educación. Op.cit. p.403

39 TUDGE, J. "Vygostki, la zona de desarrollo próximo y la colaboración entre pares: connotaciones para la práctica del aula". En Vygostki y educación. p. 189

40 A esto Vigostki lo denomina nivel real de desarrollo Cfr. VYGOTSKI, L. "Desarrollo y aprendizaje". En El desarrollo de los procesos psicológicos superiores. Op. cit. p. 133

41 HEDEGAARD, Mariane. "La zona de desarrollo próximo como base para la enseñanza". En Vygostki y educación . Op.cit. p. 404

42 Ibídem. 
Esto deja entrever, una respuesta afirmativa a la pregunta del presente escrito. Es posible hablar de aprendizajes autónomos en el discurso pedagógico, pues, como se dejó ver en el primer apartado, el constructivismo hace parte de los discursos pedagógicos por una regla de recontextualización, en la que un discurso, que en primer momento que se encuentra en el ámbito de la psicología, es apropiado en el contexto pedagógico y asumido como discurso, que permite regular y distribuir los demás que se manejan al interior de las instituciones educativas.

Pero considero que aquí no queda la cuestión, pues cabe preguntarse cómo, en el ámbito de lo práctico, se da ese desarrollo de aprendizajes autónomos, más ese no es el cometido del presente escrito, ya que abocaría a analizar las prácticas y no sólo el discurso, que es lo que le interesa a este escrito. Además, es algo que evoca a pensar la educación, hoy en día, la cual no se preocupa sólo por brindar cantidad de contenidos al educando, sino también, por la calidad de docentes que brindan una formación educativa a los jóvenes de hoy ${ }^{43}$. En estos tiempos se ha escuchado hablar sobre los niveles de calidad que deben tener tanto las instituciones educativas como los docentes. Pero, cómo se sabe, si esos niveles de calidad cumplen con las necesidades del educando y si cumplen con ellas, qué clase de educación se les está brindando. Lo que arroja a plantear un problema: el de saber si es necesario que exista un docente para que el estudiante desarrolle un conocimiento. $Y$ si es necesario, cuál es su papel dentro de la formación y cómo debe desempeñar ese papel dentro del aula.

Es en este punto, en el que quiero dejar al lector a manera de sugerencia un ejemplo, a través del cual se muestra cómo el discurso pedagógico constructivista, llevado a la práctica, busca el desarrollo de aprendizajes autónomos tal y como se concluye en presente apartado.
La propuesta se encuentra contenida en texto El maestro ignorante de Ranciere Jacques, quien trabaja una metodología encontrada en los escritos de Joseph Jacotot. En el texto se plantea que las metodologías explicativas son el arte de la distancia. El arte de la distancia consiste en "saber reconocer la distancia entre el material enseñado y el sujeto a instruir, la distancia también entre el aprender y el comprender ${ }^{\prime \prime 4}$, éste es el arte que el docente debe vislumbrar para poder llegar al estudiante. El autor de la obra El maestro ignorante presenta una estructura que busca hacer un recorrido tanto por las antiguas metodologías explicativas como exponer una nueva metodología, en la que la explicación es relegada a un último lugar.

Además, el método de Jacotot se presenta como una nueva alternativa para reflexionar cómo se puede pasar del simple discurrir a la práctica, manteniendo presente el objetivo de desarrollar aprendizajes autónomos. Esto implicaría un reconocimiento del rol tanto del docente como del estudiante en los procesos educativos y exhortaría a revaluar los métodos que consideran la existencia de inteligencias inferiores y superiores en la formación del ser humano, solventando la brecha que surge al considerar al estudiante como un ente más de la educación, al cual hay que llenar de conocimientos e impartirle normas para la construcción de su propia personalidad. Pero con ello, lo que se ha hecho es despersonalizar la educación y crear sistemas reproductores de información, mas no como lo expresa la ley "el alumno o educando es el centro del proceso educativo y debe participara activamente en su propia formación integral”45.

Esta propuesta, desde los postulados "enseñar lo que ignora y el poder del ignorante", lo que da es la posibilidad de que el individuo se haga responsable de su propio proceso, sin alejarse de su propia realidad, partiendo de esta misma, para construir un mundo de la vida que implica al otro como

43 "El educador es el orientador en los establecimientos educativos, de un proceso de formación, enseñanza y aprendizaje de los educandos, acorde con las expectativas sociales, culturales, éticas y morales de la familia y la sociedad" Ministerio de Educación Nacional. Ley general de educación. 115 de 1994. "Articulo 104: El educador". MEN, Bogotá, 1994. p.79

44 Ibídem. p 13 
participante activo de las experiencias que se entretejen en el entramado de los procesos educativos, lo cual se evidencia como una apuesta constructivista.

Se podría concluir, resaltando que si lo que se busca es una educación en la cual el estudiante sea un agente activo con pensamiento critico, reflexivo y creativo ante la realidad, la primera apuesta a considerar en el ámbito de la educación, consiste en cambiar las perspectivas culturales que se tienen frente al rol de cada uno de los individuos partícipes de los procesos de formación de un ser humano. Esto implica reformular las formas en que se asumen los discursos y las apuestas que se realizan ante ellos, teniendo en claro que el desarrollo de aprendizajes autónomos están sujetas al discurrir histórico. Cabe agregar aquí, que es necesario también pensar las implicaciones y las apuestas a las que tendría que llegar la educación colombiana si se empleará un modelo como el de Jacotot (y seguramente otras que le apunten a la autonomía), qué cambios y qué horizontes estarían en el discurrir pedagógico dispuesto a desarrollar. Con esto quiero dejar abierta la posibilidad de pensar el modelo a la luz de nuestra realidad, pues responder preguntas como las que se plantean implicarían otro trabajo distinto, en el cual se analice a profundidad el contexto colombiano y se establezcan las respectivas relaciones en los planteamientos pedagógicos, lo cual desviaría la cuestión a otros asuntos y evocaría la posibilidad de analizar los discursos pedagógicos en realidades concretas desde una perspectiva histórico-social, que no es el tema que concierne a la reflexión que se abordo en el presente texto.

Pero entonces, qué se puede concluir de la pregunta que se planteó al inicio de este escrito. Lo primero es que, si se tienen en cuenta que la escuela es una institución regularizadora, consta de unos discursos que le permiten realizar este fin, a los que se denominan como discursos pedagógicos, los cuales, desde las perspectivas de Mario Díaz y Bersntein, son discursos que se convierten en procesos de recontextualización, o más bien, se apropian de otros discursos. Un ejemplo de esto ocurre con el discurso psicológico del constructivismo, pues surge en un ámbito distinto al educativo, pero sus planteamientos son adaptados a su discurrir. Lo cual permitió limitar más la reflexión teórica del presente artículo, ya que al entender al discurso constructivista como un discurso pedagógico, se puede analizar a su interior, cómo es que se puede hablar de aprendizajes autónomos desde los discursos, aunque estos sean empleados como dispositivos de poder.

Llevando a realizar una mirada del discurso más amplia y menos sesgada, centrada en aquellos elementos que constituyen al discurso y que en sí mismos buscan el desarrollo de aprendizajes autónomos. En el caso del constructivismo, por ejemplo, se busca que el individuo se reconozca como persona que se autoforma, pero que, a la vez, necesita del otro para definirse y constituir su ser. Esto permite ver que la respuesta a la pregunta es posible hablar de aprendizajes autónomos en el discurso pedagógico, desde la perspectiva del constructivismo, es afirmativa, pues no es únicamente un dispositivo de poder, sino que su acción entreteje otra serie de cosas, que permiten comprender cómo desde ellos, se puede hablar de aprendizajes autónomos.

\section{REFERENCIAS}

ÁlVAREZ, Alejandro. (1990) Historia de la educación en Bogotá. Universidad Pedagógica Nacional. Bogotá

CARRETERO, Mario. (1993) "¿̇Qué es el constructivismo? En Constructwumo y educación. Aigue Grupo Editor, Buenos Aires.

BERNSTEIN, Basil. (1990) "Sobre el discurso pedagógico". En La construcción social del

45 Ministerio de Educación Nacional. Ley general de educación. 115 de 1994. "Articulo 91: El alumno o el educando". MEN, Bogotá, 1994. P.76 
discurso pedagógico. Editor: Diaz, Mario. El Griot. Bogotá.

DÍAZ, M. y MUÑOZ, J. (1990) "Practicas pedagógicas y sus relaciones de poder"'. En Pedagogía, discurso y poder. Corpodic. Bogotá.

FOUCAULT, Michel. (1970). Antropología del saber. Gredos. Madrid.

GUITIERREZ, Rafael. (1986) Universidad y sociedad. "Educación para la mayoría de edad un dialogo entre Teodoro W. Adorno y Hellmut Becker. Fundación editorial argumentos crear arte. Bogota.

HEDEGAARD, Mariane. (1993) "La zona de desarrollo próximo como base para la enseñanza". En Vygostki y educación. Comp: MOLL, Luis. Alque. Buenos Aires.

HERNADEZ, Gerardo. (1998) Paradigmas en psicología de la educación. Paidos. Mexico.

LYDDON, William. (1997) "Formas y facetas de la psicología constructivista". En Construcciones de la experiencia humana comp.. PAKMAN, Marcelo. Gedisa, Barcelona.

Ministerio de Educación Nacional. (1994) Ley general de educación. 115 de 1994. MEN, Bogotá.

(2006) Sentido de los lineamientos curriculares. MEN, Bogotá.

MUEL, Francine. (1993) Espacios de poder. Trotta. Sevilla.

MCLAREN, Peter. (2003) Pedagogía, identidad y poder. Los educadores frente al multiculturalismo. Homo Sapiens. Rosario.

PIAGET, Jean. (1941) La autonomía en la escuela. Serie: La escuela activa no.6. Losada. Buenos Aires

, Jean. (1995) "El tiempo y el desarrollo intelectual del niño". En Seis estudios de Psicología. Labor. Bogotá.
PORLAN, Rafael. (1993) "Conocimiento didáctico. En constructivismo y escuda". Diada Editorial, Sevilla, 1 edición sep. 1993, 5a edición abril 1998.

TUDGE, J. (1993) "Vygostki, la zona de desarrollo próximo y la colaboración entre pares: connotaciones para la práctica del aula". En Vygostki y educación. Comp: MOLL, Luis. Alque. Buenos Aires.

RANCIERE, J. (2002) El maestro ignorante. Trad. Estrach Nuria. Leartes, Barcelona.

ROUSSEAU, Jean-Jacques. (1987) Emilio o de la educación. Alianza. Barcelona.

VYGOTSKI, L. 1989 "Desarrollo y aprendizaje". En El desarrollo de los procesos psicológicos superiores. Grijalbo, Barcelona.

L. (1993) "Las raíces genéticas del pensamiento y lenguaje". En Obras escogidas. Visor. Madrid.

WERTSCH, James. 1995 Vygotski y la formación social de la mente. "El método de Vygotski". Piados. Barcelona.

Fuentes secundarias:

BERNSTEIN, Basil, (1988). Poder, educación y conciencia: sociología de la transmisión cultural. CIDE. Santiago.

BERNSTEIN, Basil. (1998). Pedagogía, control simbólico e identidad: teoría, investigación y crítica. Morata. Madrid.

CULLEN, Carlos A. (1996) Autonomía moral, participación democrática y cuidado del otro: bases para un currículum de formación ética y ciudadana. Buenos Aires, Novedades Educativas.

CHADWICK, Clifron. "La psicología de aprendizaje del enfoque constructivista". En Red Revista Latinoamericana de Estudios Educativos. México, 2006.

FERMOSO, Julio. (1996) Más allá de la 
autonomía. París, CRE, Columbus, UNESCO.

JOSEP M. Andrés (2003) Autonomía y responsabilidad. Barcelona. Cristianisme i Justicía.

NIEVES, Celio. (2007) "Al debate la educación pública". En Revista Javeriana Vol. 143, no. 733. p. $46-54$

REBOUL, Olivier. (1972) ¿̇Transformar la sociedad? ¿̇Transformar la educación?. Trad. Carlos Puerto. Madrid, Narcea.

SEGUIER, Michel. (1974) Pedagogía de la responsabilidad. Trad. José María de Llanos. Madrid, Marsiega.

LYDDON, William. "Formas y facetas de la psicología constructivista".

PANEA, Jose Manuel. (Sep. -Dic. 1998) "Discernimiento y ejecución de la ética de Kant (A propósito de los limites de la autonomía en el marco de la mera razón)". En Pensamiento: Revista de investigación e información Filosófica. Vol. 54, no. 210.

Wlttgenstein, L. Investigaciones Filosóficas. Gredos, Madrid, 1995. 